\title{
Corrosion Inhibition Performance and Adsorption Mechanism of Novel Quinazoline Schiff Base on Low Alloy Steel in HCl Media
}

\author{
Ghulamullah Khan ${ }^{1,2, *}$, Wan Jeffrey Basirun ${ }^{3}$, Ahmed Badarudin Bin Mohamad Badry ${ }^{1}$, \\ Salim Newaz Kazi ${ }^{1}$, Pervaiz Ahmed ${ }^{4}$, Syed Muzamil Ahmed ${ }^{1}$, Ghulam Mustafa Khan ${ }^{5}$ \\ ${ }^{1}$ Department of Mechanical Engineering, Faculty of Engineering, University of Malaya 50603, \\ MALAYSIA \\ ${ }^{2}$ Department of Chemical Engineering, Faculty of Engineering, Balochistan University of Information \\ Technology, Engineering and Management Sciences, Airport Road, Baleli, Quetta 87650, \\ Balochistan, PAKISTAN \\ ${ }^{3}$ Department of Chemistry, Faculty of Science, University of Malaya 50603, MALAYSIA \\ ${ }^{4}$ Department of Physics, Azad Jammu and Kashmir University, Muzaffarabad 13100, PAKISTAN \\ ${ }^{5}$ Department of Chemistry, Faculty of Science, University of Balochistan, Quetta 87500, Balochistan, \\ PAKISTAN \\ *E-mail: ghulamullahkhan73@gmail.com
}

doi: $10.12964 / 2018.12 .40$

Received: 27 July 2018 / Accepted: 21 September 2018 / Published: 5 November 2018

The inhibition performance of synthesized Quinazoline Schiff Bases 2-(3,3-Dimethyl-2,3-dihydroindol-2-ylidene)-3-[(2-hydroxyphenyl) imino] propylidene (DHIP1) and 2-(3,3-Dimethyl-2,3-dihydroindol-2-ylidene)-3-[(2-hydroxyphenly) imino] propanal (DHIP2) on low carbon steel (LAS) in $1 \mathrm{M} \mathrm{HCl}$ has been examined using weight loss, electrochemical measurements and scanning electron microscopy (SEM). The obtained experimental results indicated that both DHIP1 and DHIP2 have fairly enhanced the corrosion resistance of LAS and extremely exhibited better inhibitive efficiencies at a concentration of $5 \mathrm{mM}$. The results of potentiodynamic polarization results clarified that investigated Schiff Bases acts as mixed-type inhibitors and follow Langmuir adsorption isotherm is fitted well for adsorption. It was found that the inhibition efficiency increases with increase in inhibitor concentration as confirmed by all the measurements.

Keywords: Low alloy steel; inhibition corrosion; adsorption; EIS; Quinazoline Schiff Bases

\section{$\underline{\text { FULL TEXT }}$}

(C) 2018 The Authors. Published by ESG (www.electrochemsci.org). This article is an open access article distributed under the terms and conditions of the Creative Commons Attribution license (http://creativecommons.org/licenses/by/4.0/). 